\title{
A 2D typology generator for historical masonry elements
}

\author{
Shenghan Zhang, Martin Hofmann, Katrin Beyer* \\ Earthquake Engineering and Structural Dynamics (EESD), Institute of Civil Engineering, \\ ENAC, cole Polytechnique Fdrale de Lausanne (EPFL), Switzerland
}

\begin{abstract}
The mechanical response of stone masonry depends on the properties of the components and also on the typology created by the stone units and the mortar joints. While the influence of the component strength on masonry is relatively well studied, mainly due to the difficulty of varying the masonry typology systematically, few research studies have been devoted to its influence on masonry properties. This paper focuses on generation and calibration of masonry typologies, which serves as foundation for further numerical investigation. To this purpose, we develop a typology generator based on relevant research in computer vision. To characterize different typologies quantitatively, we also develop an objective method to compute the line of minimum trace directly from the image of stone masonry based on graph theory. The code and recommendations for the parameter choices are publicly available online. Altogether, this paper provides a useful tool for researchers to study systematically the influence of historical stone masonry typologies.

Keywords: historical masonry, typology generator, stone pattern, line of minimum trace, detailed micro-modeling
\end{abstract}

2010 MSC: 00-01, 99-00

\footnotetext{
* Corresponding author

Email address: katrin.beyer@epfl.ch (Katrin Beyer)
} 


\section{Introduction}

Stone masonry is one of the oldest construction materials and can be found in many of today's cultural heritage structures. Stone masonry buildings are also among the most vulnerable structures under earthquake loading [1, 2] and

5 other disasters. Effectively planning strengthening interventions requires a good understanding of their seismic behavior 3 . However, understanding the mechanical behavior of stone masonry elements is a long-standing challenge in civil engineering [4].

One traditional way in this field is to focus on a certain type of masonry 10 [5, 6] and to obtain global strength values or deformation capacities through a series of experimental tests. Although useful engineering indices can be obtained in this way, the substantial variety of masonry and the difficulty of controlling certain parameters in experiments (e.g. stone shape, stone size distribution, distribution of material properties within the element) make it impossible to exhaust all typologies. Thus a deeper understanding of the material is required.

The mechanical response of stone masonry is determined by the properties of the components and also dependent on the typology created by the stone units and the mortar joints. There have been already some studies on the influence of the component strength on masonry properties [7, 8. Research on the influence of the typology on the masonry properties is, however, relatively scarce. One of these studies is the pioneering work on interlocking by Mann and Müller 9. Recent developments along this line include the work by Calderini et al. [10, 11. However, these studies concentrated only on regular masonry (e.g., brick masonry) for which the generation and the quantification of the typology 25 are much simpler than for irregular stone masonry. The same limitation also exists for various homogenization methods [12] where a representative volume element is based on brick masonry for which the typology is easy to define.

Two major obstacles that hinder related research on historical stone masonry are the difficulties of systematically generating and accurately quantifying patterns for different typologies. Due to these limitations, in previous research, 
e.g., [13, 14, typologies were only compared and differentiated qualitatively. Recently, the concept of the line of minimum trace (LMT) [15, 11, 16] has been put forward to quantitatively characterize the masonry typology. However, in these works the line of minimum trace is evaluated manually, which is time-consuming and can even lead to subjective results if possible paths are discarded due to misjudgment.

To address the two obstacles above, this paper is devoted to complement existing research on stone masonry by developing the first generator for stone masonry typologies and by developing a tool for calculating the LMT automatically. These two contributions will allow to conduct systematic numerical studies on the effect of stone masonry typologies on the resulting element strength and deformation properties and will also benefit other research objectives that are based on the micro-structure, e.g., the development of homogenization and multi-scale modeling methods for stone masonry.

The structure of the paper is as follows: Section 2 of this paper introduces the stone masonry typologies that are typically distinguished and which we aim to generate using our micro-structure simulator. In Section 3 we describe the typology generator. This part of research is based on related research in computer vision [17. In order to represent real masonry typologies, important 50 improvements are introduced, including the implementation of the erosion process generating mortar layers of varying thickness and the Voronoi splitting of certain regions [18, 19] in order to obtain more irregular patterns. Section 4 introduces the algorithm for computing the LMT. To automate the process, we reformulate the problem as a shortest path problem in graph theory [20] and use the classical Dijkstra's algorithm 21] to calculate the LMT. In reality, cracks tend to follow the mortar-stone interfaces because interfaces are normally weaker than the mortar itself. In order to consider this physical reality, we further generalize the definition of the LMT by assigning different weights to the interface and the mortar. Section 5 presents the application of the typology generator and a comparison with reference patterns. To illustrate how the typology generator can be used with the detailed micro-modeling method, we transform 
the patterns into finite element meshes and analyze the compressive strength of the generated samples.

\section{Classification of stone masonry typologies}

Today, masonry typologies are classified by comparing their pattern visually to example patterns in design codes. Typically, five classes are distinguished (a definition of these classes can be found in Table C8A.2.1 [22]; the various typologies are shown in Figure 1 taken from [6]):

- Class A: irregular stone masonry, with pebbles, irregular stone units;

- Class B: uncut stone masonry;

- Class C: cut stone masonry with good bonds;

- Class D: soft stone regular masonry (built with tuff or sandstone blocks);

- Class E: Ashlar masonry, built with sufficiently resistant blocks.

As a sixth class, we introduce block (Ashlar) masonry, where the blocks are perfectly rectangular and all blocks of one row have the same height. This typology covers cut stone (Ashlar) masonry as well as modern brick masonry, where all blocks have the same size.

A first step towards a non-discrete classification system is the Masonry Quality Index (MQI) developed by Borri et al. 23. based on a procedure by Binda

so et al. 24 for assessing the quality of stone masonry and its compliance to the rules of the art [24, 25]. It accounts for the mechanical properties of the constituents, the conservation state, and the texture of the masonry. The latter is evaluated by considering qualitatively the dimensions of the stones, their shape, the characteristics of the wall section (including the connection of leaves), the horizontality of the bed-joints, and the staggering of the vertical joints. The latter parameter is determined quantitatively using the concept of the length of the Line of Minimum Trace (LMT), which was proposed by Doglioni et al. [16]. The LMT is defined as the minimum length of a line passing only through 


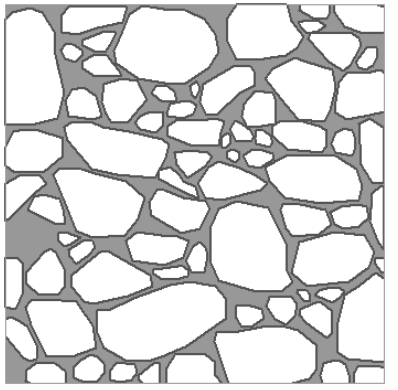

(a) Typology A

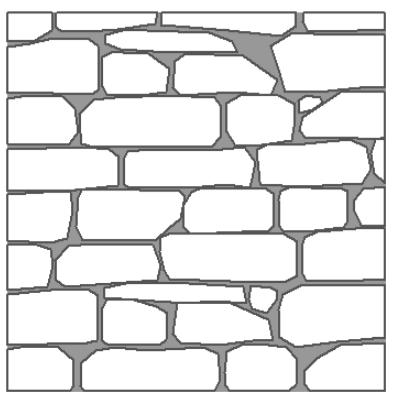

(d) Typology D

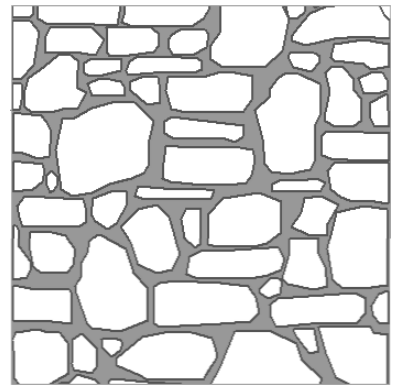

(b) Typology B

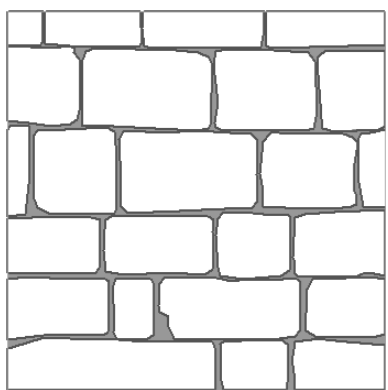

(e) Typology E

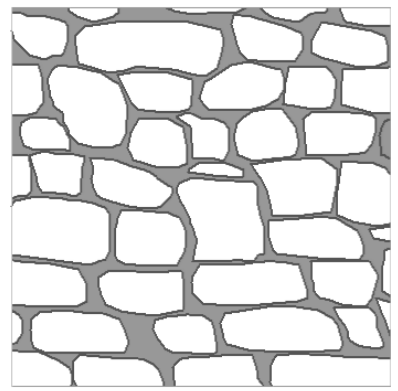

(c) Typology C

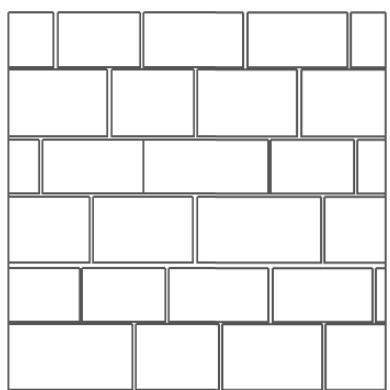

(f) Typology E1

Figure 1: Patterns of five stone masonry typologies that are defined by the Italian code [22] and a block masonrypattern. Sketches from Vanin et al. 6]

mortar joints connecting two points that are vertically aligned and at a distance $h_{v}$.

$$
\mathrm{LMT}=\frac{\text { Min. trace through joints }}{h_{v}}
$$

\section{Typology generator}

This section outlines the algorithms used for generating the various masonry typologies by means of a typology generator. The process can be divided into three principal steps: i) generating a stone pattern; ii) creating the mortar

layer; iii) post-processing the generated typology (sieving, sampling). These three parts of the typology generator are summarized in Algorithm 1. 


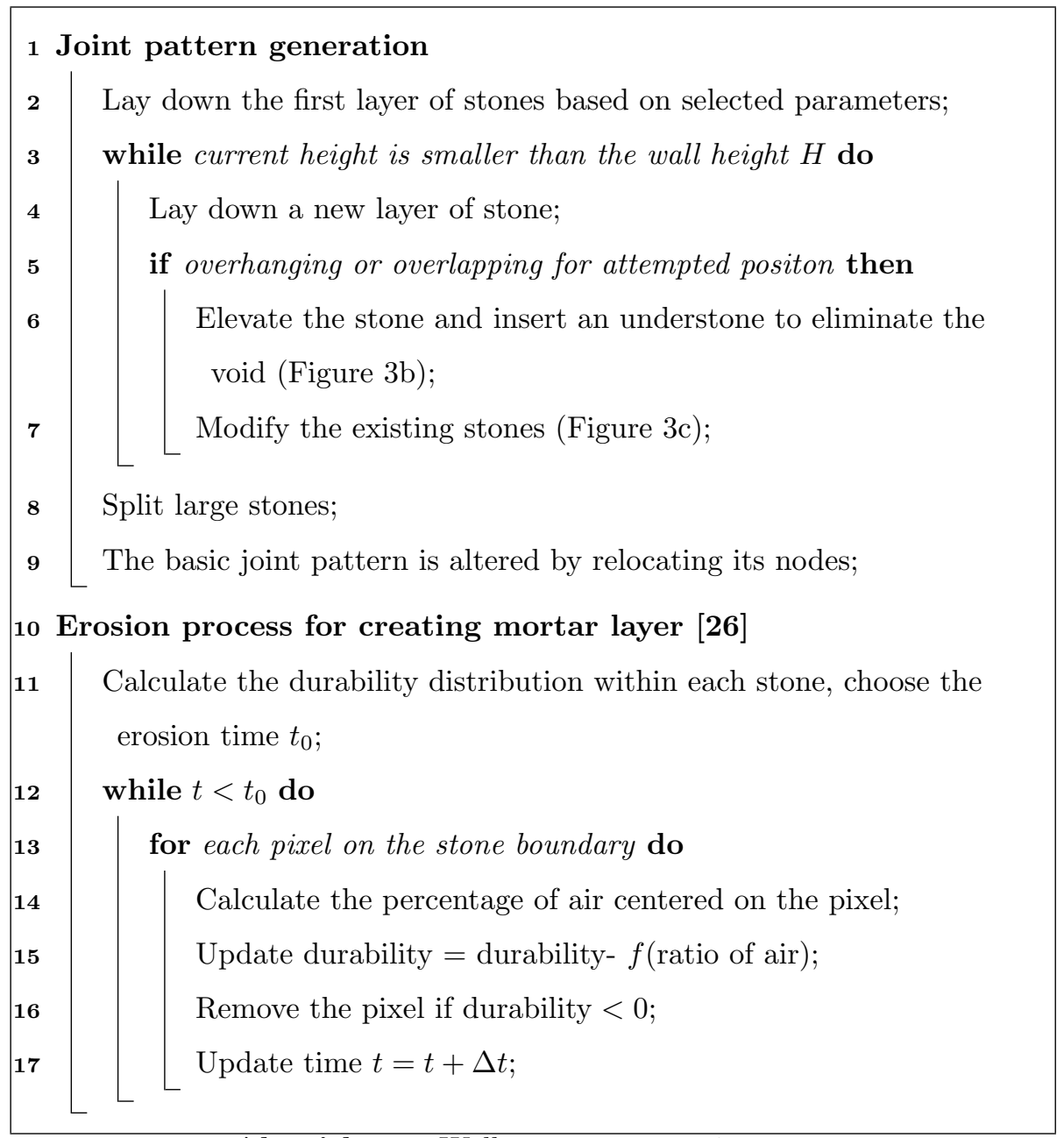

Algorithm 1: Wall pattern generation. 


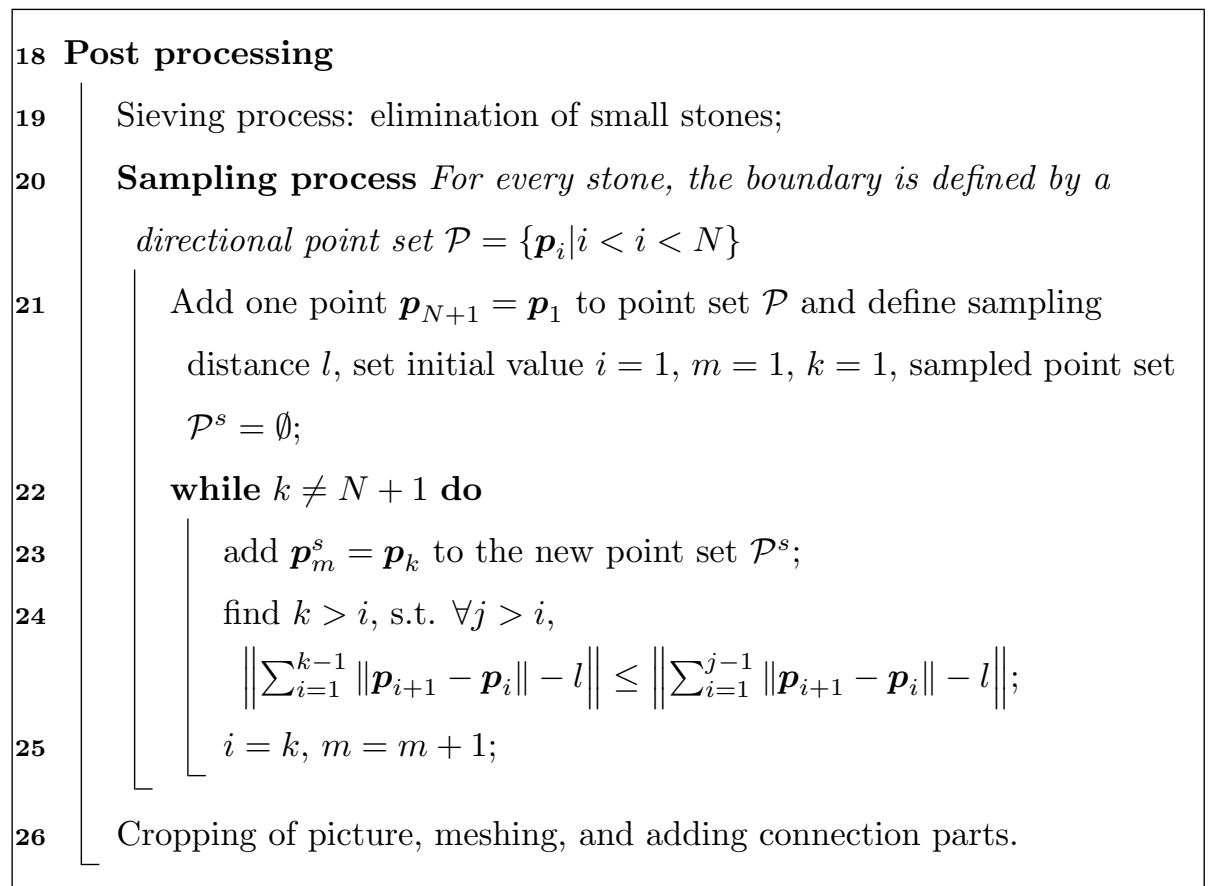

Algorithm 1: Wall pattern generation. (continue)

\subsection{Stone pattern generation}

The typology generator is built on related research in computer vision by Miyata [17, originally proposed as a method for synthesizing stone masonry wall patterns (as can be seen in Figure 2, the pattern generated with the original algorithm is still far from the typical masonry typology in Figure 1).

The objective of the stone pattern simulator is to generate a cellular structure such that each stone is contained in a single cell. The stone pattern generation can be divided into two steps: the generation of the basic joint pattern and the relocation of nodes. The basic joint pattern is created by laying down stone by stone, from bottom to top, from left to right. The dimension of each stone (height $h_{s}$, width $l_{s}$ ) is determined by the following random function:

$$
h_{s}=h_{s 0}\left(1+\sigma_{h} \cdot N_{x}\right), \quad l_{s}=l_{s 0}\left(1+\sigma_{l} \cdot N_{y}\right)
$$

in which $h_{s 0}, l_{s 0}$ are the mean height and width of the stone, $\sigma_{h}$ and $\sigma_{l}$ are the corresponding standard deviations (all four parameters can be functions 


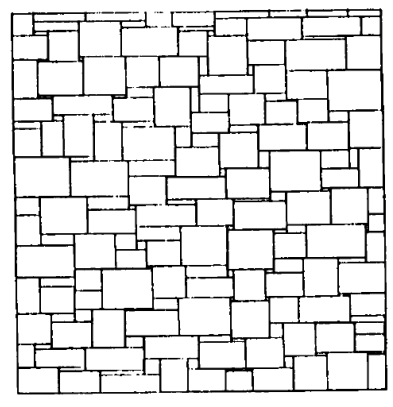

(a) example of basic joint pattern

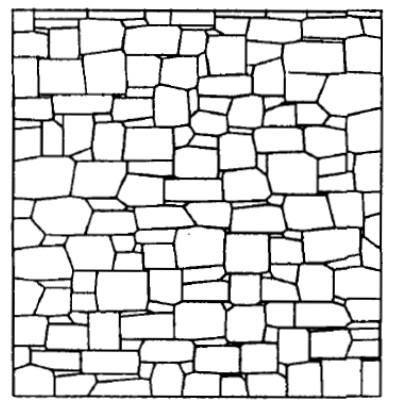

(b) joint pattern after shaking

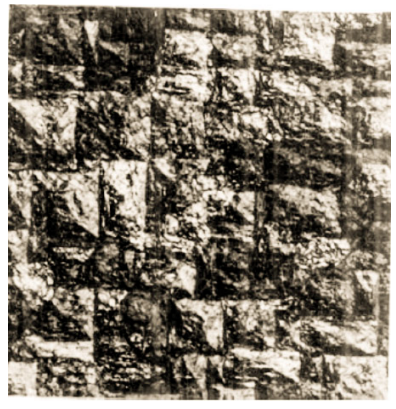

(c) $3 \mathrm{D}$ rendered pattern

Figure 2: Stone masonry patterns generated using Miyata's method 17.

of the positions of the stone, e.g., they can be specified as a function of the stone-pattern-generation option that uses Voronoi cells [19]. Voronoi cells are generated using Voronoi splitting, in which a user-defined number of seed nodes are randomly placed in a cell. The cell is then split in such a way that every 

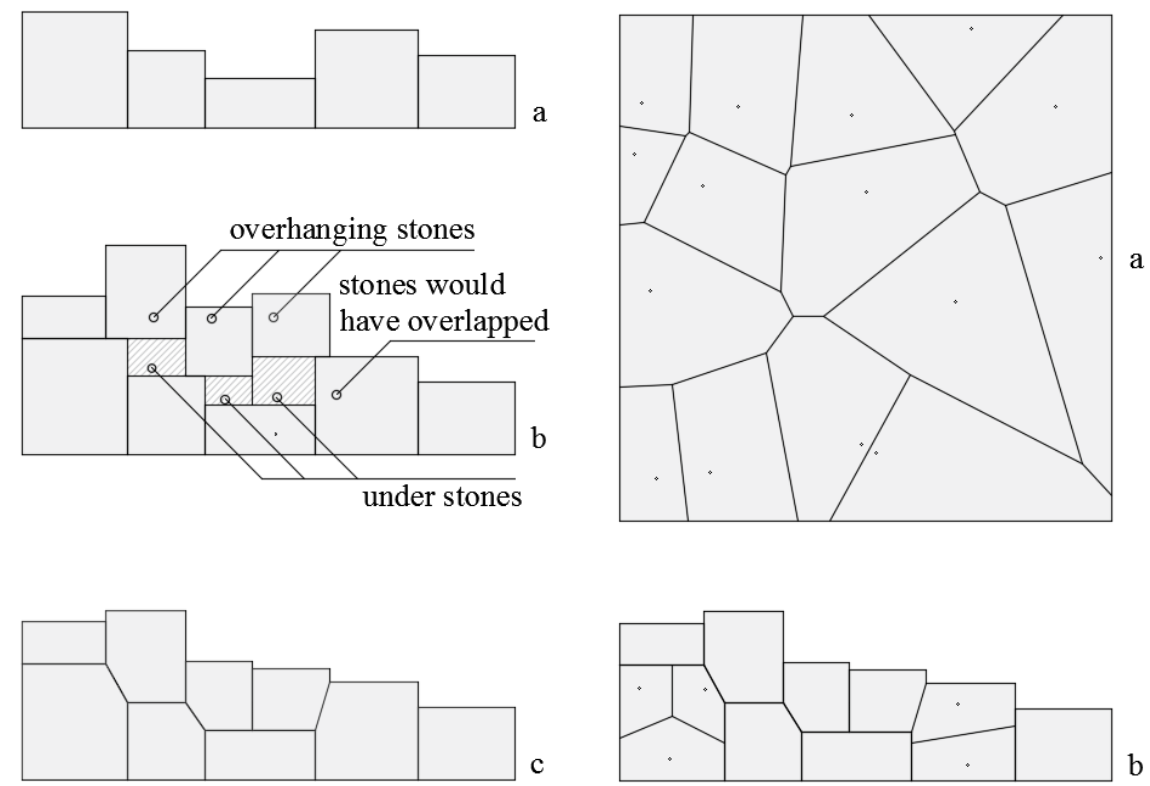

Figure 3: Illustration of the construction pro-

Figure 4: Vorognoi spitting of stones. cess.

point in a given partition is closer to its generating seed node than to any other seed node. As illustrated by Figure 4, Voronoi cells can be used to generate patterns for a whole region, which is more representative only if the region is totally unstructured (e.g., rubble masonry), or split selected stones (e.g. stones with an area that is larger than a specified threshold value). To illustrate the method, Figure $4 \mathrm{~b}$ shows the result of applying Voronoi splitting to Figure 3 .

After generating the basic joint pattern, the coordinates of the nodes are relocated randomly in order to create a more irregular pattern [17]:

$$
x_{n}=x_{n 0}\left(1+\sigma_{x n} \cdot N_{x}\right), \quad y_{n}=y_{n 0}\left(1+\sigma_{y n} \cdot N_{y}\right)
$$

in which $\left(x_{n 0}, y_{n 0}\right)$ are the original coordinates from the basic joint pattern, $\left(x_{n}, y_{n}\right)$ are the relocated coordinates, $\sigma_{x n}$ and $\sigma_{y n}$ are normalized standard deviations in each direction, $N_{x}$ and $N_{y}$ are independent standard normal random variables. The relocation of the coordinates of the nodes $\left(x_{n}, y_{n}\right)$ is confined 


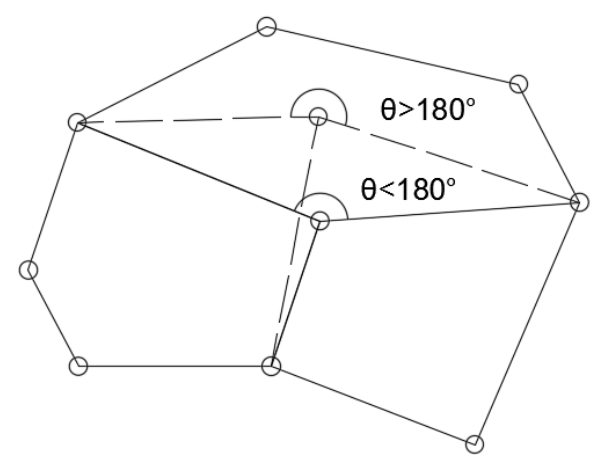

Figure 5: Illustration of convexity index $\theta$.

by a check whether the maximum interior angle of the polygon is smaller than 135 a specified threshold angle $\theta_{\max }$, as illustrated in Figure 5. Miyata [17] set $\theta_{\max }$ to $180^{\circ}$; if $\theta_{\max }$ is larger than $180^{\circ}$, a certain level of concaveness of the stone boundary is tolerated. The joint pattern created above is suitable for the simplified-micro modeling approach where mortar layers are represented by zero thickness interface elements [12, 27, 28]. An approach for creating a uniform thickness mortar layer is proposed by Miyata [17. To create a mortar layer of non-uniform thickness and rounded stones edges, we use the weathering algorithm in Jones et al. [26], which was developed to simulate the wind erosion of rocks.

The eroding process is modeled for each stone independently. To this end, each stone is placed on a uniform pixel grid. Each pixel representing the stone, i.e., each pixel that lies within the stone boundary, is initialized with a durability value. The pixels outside the stones, which represent the air, have a durability of zero. For each pixel on a stone boundary, the air ratio $\rho_{\text {air }}$ is determined by drawing a circle with diameter $D$ that is centered on the pixel and counting the pixels within the circle. The air ratio is then defined as

$$
\rho_{\text {air }}=\frac{n_{\text {air }}}{n_{\text {tot }}}
$$

in which $n_{\text {air }}$ is the total number of air pixels and $n_{\text {tot }}$ is the number of pixels within the circle. For instance, if the pixel lies on a straight boundary, $\rho_{\text {air }}=0.5$. 
The diameter $D$ is a user-defined parameter in the typology generator. The larger the diameter, the more the corners will be rounded.

The erosion of the stone is modeled as a time evolving process. Without losing generality, considering from time step $m$ to $m+1$, the pixel is eroded and the remaining durability is calculated by:

$$
d_{m+1}=d_{m}-f\left(\rho_{\text {air }}\right)=d_{m}-\alpha \rho_{\text {air }}^{r}
$$

in which $\alpha, r$, and the time step controlling the speed and shape of the erosion are currently taken as a constant value. Note that the specific form of $f\left(\rho_{\text {air }}\right)$ is not given in Jones et al. 26]. The parameter $f\left(\rho_{\text {air }}\right)$ should be a monotonically increasing function with $f(0)=0$. Here, we choose the function form $f\left(\rho_{\text {air }}\right)=$ $\alpha \rho_{\text {air }}^{r}$, which will be shown later to already suffice our needs. Increasing $\alpha$ speeds up the eroding process. The exponent $r$ controls the relative erosion of corners and edges, as will be illustrated in the next paragraph. If $d_{m+1} \leq 0$, the pixel is considered to be totally eroded and labeled as air. The boundary of the stone is then updated.

Figure 6 compares the eroding speed for typical air ratios with regard to different values of the exponent $r$. From Figure6a and Equation 5 , it is apparent that: (1) for $r=0$, all pixels are eroded at the same speed, resulting in a mortar layer of uniform thickness; (2) the erosion speed is positively correlated with the air ratio for $r>0$, which suggests that pixels at convex corners $\left(\rho_{\text {air }}>0.5\right)$ erode faster than pixels lying on straight lines $\left(\rho_{\text {air }}=0.5\right)$; erosion therefore smoothens convex corners creating a round stone shape. Rather than the absolute eroding speed, the relative erosion speeds for typical air ratios, which represent pixels at different positions on the stone boundary, are of interest. In Figure 6b we use the erosion of a straight line $\left(\rho_{\text {air }}=0.5\right)$ as a reference case. It shows that with increasing $r,(1)$ the speed of the rounding process for convex corners also increases; (2) for concave corners (provided $\theta_{\max }$ was set to be larger than $180^{\circ}$ ), the eroding speed is slower. Consequently, concave surfaces are likely to be eliminated during the erosion process. 


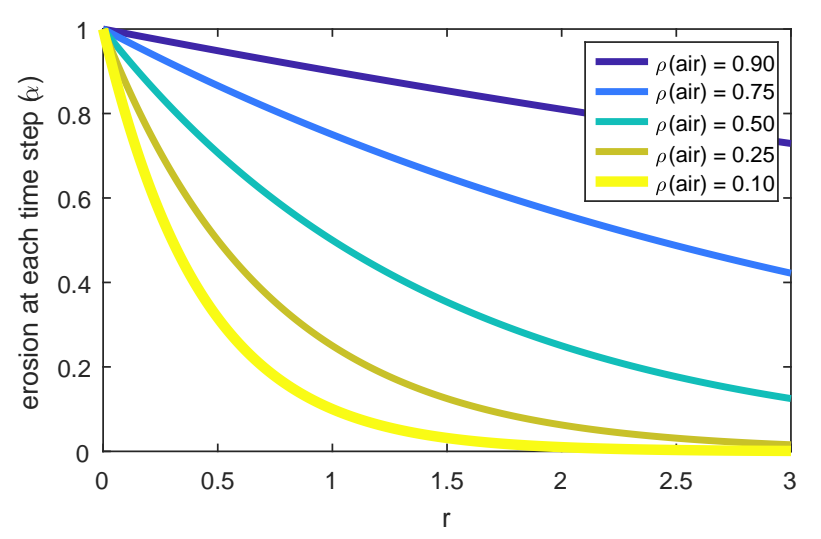

(a) absolute erosion speed

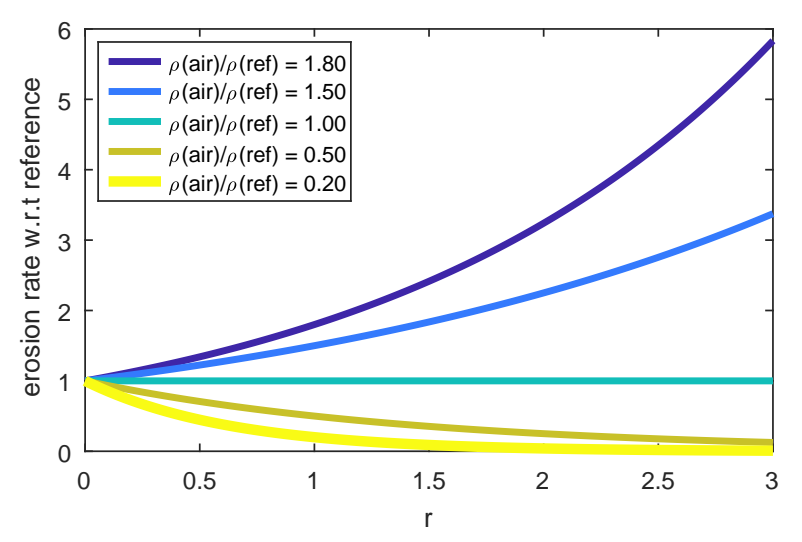

(b) relative erosion speed

Figure 6: The erosion speed with regard to the air ratio $\rho_{\text {air }}$ and $r$.

The outcome of the erosion process for a single stone is shown in Figure 7 The joint boundary of the stone prior to the erosion process is indicated in red, with the blue line indicating the eroded boundary of the stone. Figure $7 \mathrm{a}$ and $7 \mathrm{~b}$ compare the influence of $r$ for a uniform durability. The figures confirm that 175 erosion is uniform for $r=0$ and that the corners are rounded for $r=3$. To obtain a variable mortar layer thickness, the durability of the stones is modeled as a Gaussian random field using the Karhunen-Loève decomposition method [29]. In this way, each pixel is assigned with a different durability, leading to 
varying erosion along straight edges and therefore to mortar layers of varying

\subsection{Post-processing}

The boundary can be further simplified using a sampling process. Sampling the boundaries of the stones reduces the number of points and results in a polygonal approximation of the boundary. The specific process is shown in Algorithm

conditions (e.g., foundation or loading bracket). After post-processing, the micro-structure can be used to generate a finite element mesh [30, 31]. The use of the generated typologies in finite element analysis is illustrated in Section 5.4. Geometric characteristics such as the LMT can also be calculated using the

\section{Calculating the line of minimum trace to characterize the inter- locking between stones}

As outlined in the introduction, the classification of stone masonry typologies is based at present on a visual comparison with example patterns. One parameter that can be quantified is the line of minimum trace (LMT, Section 2. through mortar joints, which characterizes the interlocking between stones. This parameter has been used for the classification of brick and stone masonry [11, 16]. In the Italian code, it is used to estimate the strength of stone masonry 22]. In the current practice, the LMT is determined manually by drawing lines through mortar joints on photos of stone masonry walls and calculating the length of these lines. The approach is time-intensive and can even lead to subjective results. For this reason, we implemented Dijkstra's minimum cost path 


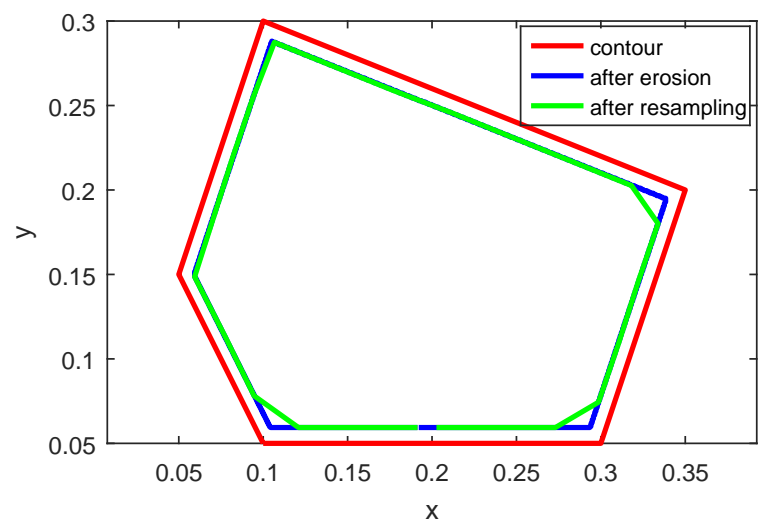

(a) eroded stone boundary with $r=0$

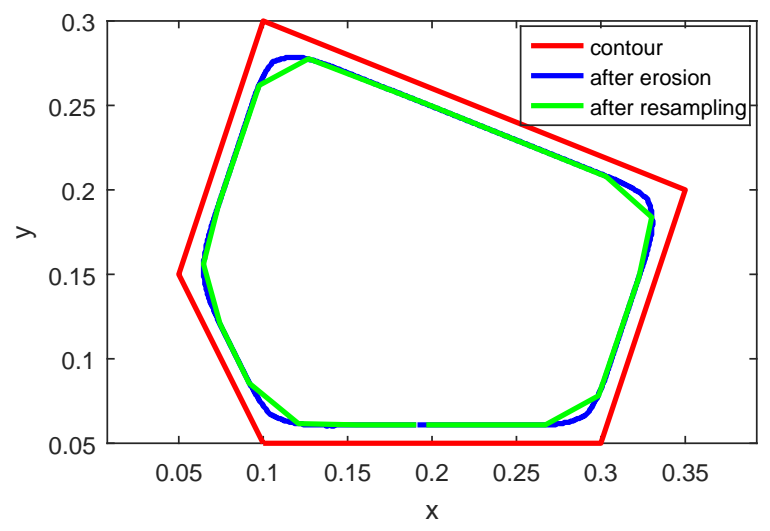

(b) eroded stone boundary with $r=3$

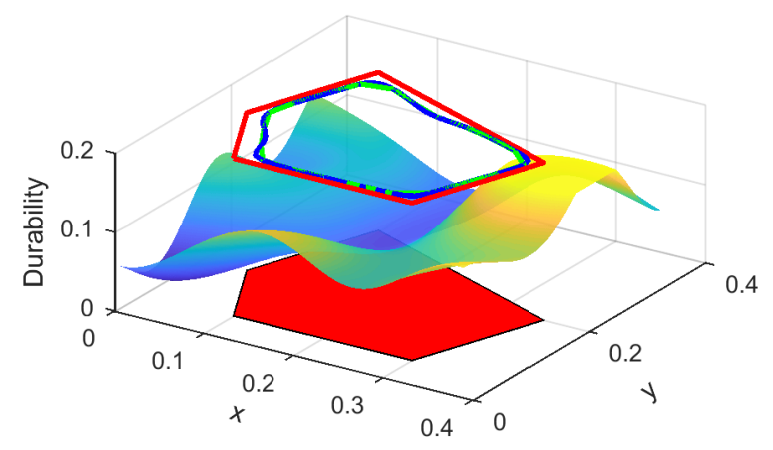

(c) random durability

Figure 7: Illustration the outcome of erosion process with one stone. 


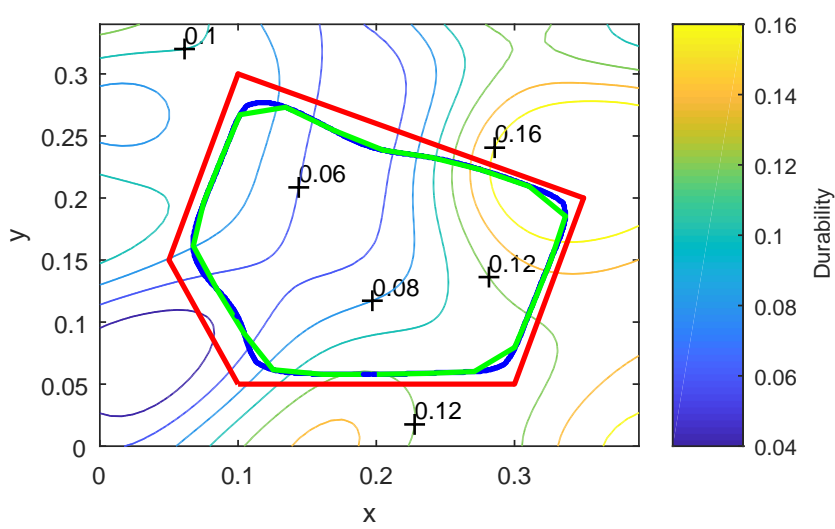

(d) responding eroded stone boundary

Figure 7: The erosion process and sampling of boundary points.

algorithm [21]. To account for the fact that cracks tend to follow mortar-stone interfaces, the algorithm is generalized and different costs are assigned to travel paths within the mortar and travel paths along mortar-stone interfaces.

To compute the LMT, we first assume that the stone boundaries have been discretized in a finite number of points $\boldsymbol{p}_{i}$. We define two points $\boldsymbol{p}_{i}$ and $\boldsymbol{p}_{j}$ to be visible [32] if the line segment joining $\boldsymbol{p}_{i}$ and $\boldsymbol{p}_{j}$ does not contain any interior points of the stones. This definition allows the segment $\boldsymbol{p}_{i} \boldsymbol{p}_{j}$ to pass through a reflex vertex or to be tangent to a polygonal edge of the stone.

A path between two points $\boldsymbol{p}_{1}$ and $\boldsymbol{p}_{n}$ is defined as a sequence of vertices $P=\left(\boldsymbol{p}_{1}, \boldsymbol{p}_{2}, \ldots, \boldsymbol{p}_{n}\right)$ such that $\boldsymbol{p}_{i}$ is visible to $\boldsymbol{p}_{i+1}$ for $1 \leq i \leq n$. If we call $\boldsymbol{e}_{i, j}$ the edge connecting $\boldsymbol{p}_{i}$ and $\boldsymbol{p}_{i+1}$, and we define a weight function $d\left(\boldsymbol{e}_{i, j}\right)$, a shortest path between $\boldsymbol{p}_{\text {start }}$ and $\boldsymbol{p}_{\text {end }}$ is defined as the path $P=\left(\boldsymbol{p}_{1}, \boldsymbol{p}_{2}, \ldots, \boldsymbol{p}_{n}\right)$ ${ }_{220}$ with $\boldsymbol{p}_{1}=\boldsymbol{p}_{\text {start }}, \boldsymbol{p}_{n}=\boldsymbol{p}_{\text {end }}$, which minimizes the $\sum_{i=1}^{n-1} d\left(\boldsymbol{e}_{i, i+1}\right), \forall n$.

The parameter LMT is defined as the total distance of the shortest path divided by the straight line connecting the start and end points (Equation 1), which is

$$
\mathrm{LMT}=\frac{\sum_{i=1}^{n-1} d\left(\boldsymbol{e}_{i, i+1}\right)}{\left\|\boldsymbol{p}_{\text {start }}-\boldsymbol{p}_{\text {end }}\right\|}
$$


Traditionally, when computing the LMT, each segment is assigned the same travel cost, i.e., $d\left(\boldsymbol{e}_{i, i+1}\right)=\left\|\boldsymbol{p}_{i+1}-\boldsymbol{p}_{i}\right\|$. When computing the LMT through mortar joints, this would, for example, lead to the LMT represented by the red line in Figure 8a. However, normally the interface of stone and mortar is much weaker than the mortar itself [33], causing most of the cracks to follow the interface. Based on this observation, we generalize the definition of the LMT as follows:

- $0<\alpha \leq 1$ as the ratio of the travel cost along the interface to the travel cost within the mortar, i.e., traveling along the interfaces is easier;

- define $d\left(\boldsymbol{e}_{i, i+1}\right)=\alpha\left\|\boldsymbol{p}_{i+1}-\boldsymbol{p}_{i}\right\|$ if the segment $\boldsymbol{p}_{i} \boldsymbol{p}_{i+1}$ coincides with the stone boundary, i.e., traveling along the interfaces;

- define $d\left(\boldsymbol{e}_{i, i+1}\right)=\left\|\boldsymbol{p}_{i+1}-\boldsymbol{p}_{i}\right\|$ otherwise

A value of $\alpha=1.0$ means that mortar and interface are assigned the same travel cost; a value of $\alpha=0.0$ refers to the case when only the segments through the mortar are counted. We suggest that the parameter $\alpha$ can be taken as the ratio of fracture energies, therefore roughly taking on values between $0.1-0.5$ [33. An example of the shortest path for $\alpha<1$ is shown in Figure $8 \mathrm{a}$ (blue line). For brick masonry, the closed form of the interlocking parameter can be readily calculated. Figure $8 \mathrm{~b}$ compares the variation of the interlocking parameter with regard to $\alpha$. The adjacent points are constructed by the visibility polygon, which is the possibly unbounded polygonal region of all points visible from a point [34. The shortest path between two points is calculated using a classical Dijkstra's minimum cost path algorithm [21, as summarized below in Algorithm 2, The accuracy of the computed value depends on the discretization of the points on the stone boundaries. We conducted a convergence study for the example shown in Figure 8a. The error with regard to the number of points on the boundary is shown in Figure 8c. It shows that for all three values of $\alpha$, as the number of points on the boundary increases, the calculated LMT approaches the analytical solution. 


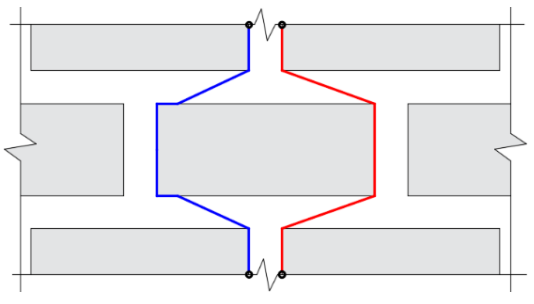

(a) Illustration of the length of minimum trace for $\alpha=1.0$ and $\alpha=0.5$

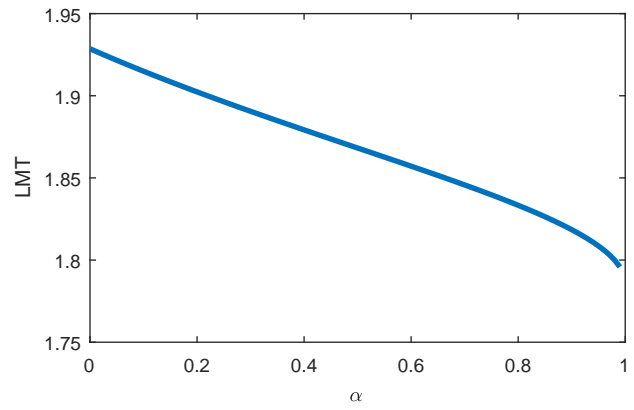

(b) closed form solution for the line of minimum trace for a unit cell

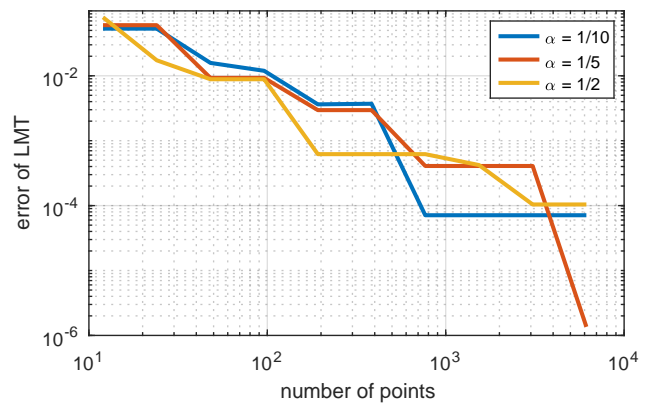

(c) error with regard to the closed-form solution as a function of the discretization of the boundary

Figure 8: Illustration and analysis of LMT. 
1 Define start point and end point;

2 Set the initial node as current. Mark all other nodes as unvisited. Create a set of all the unvisited nodes called the unvisited set; set a tentative distance $\theta$ to the start point and infinity to all other nodes;

3 while end point is not visited do

$4 \quad$ For the current node, construct a visibility graph (which includes all the points that can be reached directly from the current node). Set all the points in this visibility graph as unvisited neighbors and calculate their tentative distances to the current node;

$5 \quad$ Compare the tentative distance to the previous assigned value and assign the smaller one;

$6 \quad$ Mark the current node as visited and mark the unvisited nodes as current nodes;

7 Select the unvisited node that is marked with the smallest tentative distance, set it as the new "current node";

Algorithm 2: Compute the line of minimum trace. 


\section{Application of the typology generator and comparison with refer- ence patterns}

The application of the typology generator is discussed in this section. In Section 5.1. we compare how real joint patterns can be reproduced using the proposed typology generator. In Section 5.2 , we compare generated typologies with illustrations of typologies defined in the Italian code (Figure 1). In Section 5.3 the generated typologies is compared quantitatively to the reference typologies by computing the stone size distribution and the LMTs for various samples. In Section 5.4, to further illustrate the possible usage of the proposed typology generator, the generated samples are analyzed for a compression load using a detailed micro-modeling approach.

\subsection{Typology analysis for Vasconcelos' walls}

A comprehensive test campaign by Vasconcelos and Lourenço investigated the force-displacement behavior of various stone masonry typologies [14, 13. The most irregular typology can be classified as Typology A according to the Italian code 22. Three typical specimens from this typology are shown in Figure 9, based on which we drew the stone patterns. The third column of the figure presents possible joint patterns before erosion. The column on the right side indicates one possible basic joint pattern before relocating the nodes. We note here that the path from the left to the right is not unique. As can be seen from Figure 9, the joint pattern of all samples can be generated by combining Voronoi splitting and the joint-pattern generating technique outlined in Section 3.1. From the basic pattern and the joint pattern, the shaking distance of the nodes is calculated and the distribution of the squared distances are plotted in Figure 10, compared with the Chi-squared distribution, where the cumulative distribution function $(\mathrm{CDF})$ reads:

$$
F(x ; \sigma, k)=\frac{\gamma\left(\frac{k}{2}, \frac{x}{2 \sigma}\right)}{\Gamma\left(\frac{k}{2}\right)}
$$

in which $k$ is 2 for $2 \mathrm{D}$ problem, $\sigma$ is the standard deviation chosen to be $4 \mathrm{~cm}$ here, $\gamma$ is the lower incomplete Gamma function. To quantify the difference be- 
tween the generated samples and the Chi-squared distribution, we carried out

\subsection{Generating samples for the five typologies defined in the Italian code}

For the ease of comparison, typical representations (Figure 1 for the five typologies from Italian code are given again in the left column of Figure 11. By setting appropriate parameters, three samples are generated for each typology generate a large variety of masonry typologies with characteristics corresponding to those of the typical patterns. The parameters chosen for the generation of the patterns are available online together with the code of the typology generator.

\subsection{Quantitative comparison of generated and reference typologies}

In this section, the generated typologies and the reference typologies are compared quantitatively by analyzing the stone size distribution and the length of the line of minimum trace.

\subsubsection{Stone size distribution}

We analyzed the stone size distributions of all samples in Figure 11. To 285 eliminate the boundary effect, we eliminated all stones touching the boundary and calculated the CDFs of the stone size distribution from the remaining stones. The comparison between the generated samples and the reference typologies are summarized in Figure 12. To quantify the difference between the CDFs of generated samples and the CDF of reference typology, a two-sample

Kolmogorov-Smirnov test is carried out. The $p$-value for Typology A to $\mathrm{E}$ is 0.0244, 0.9189, 0.6834, 0.2157, 0.9606, respectively. For Typology B to E, the 

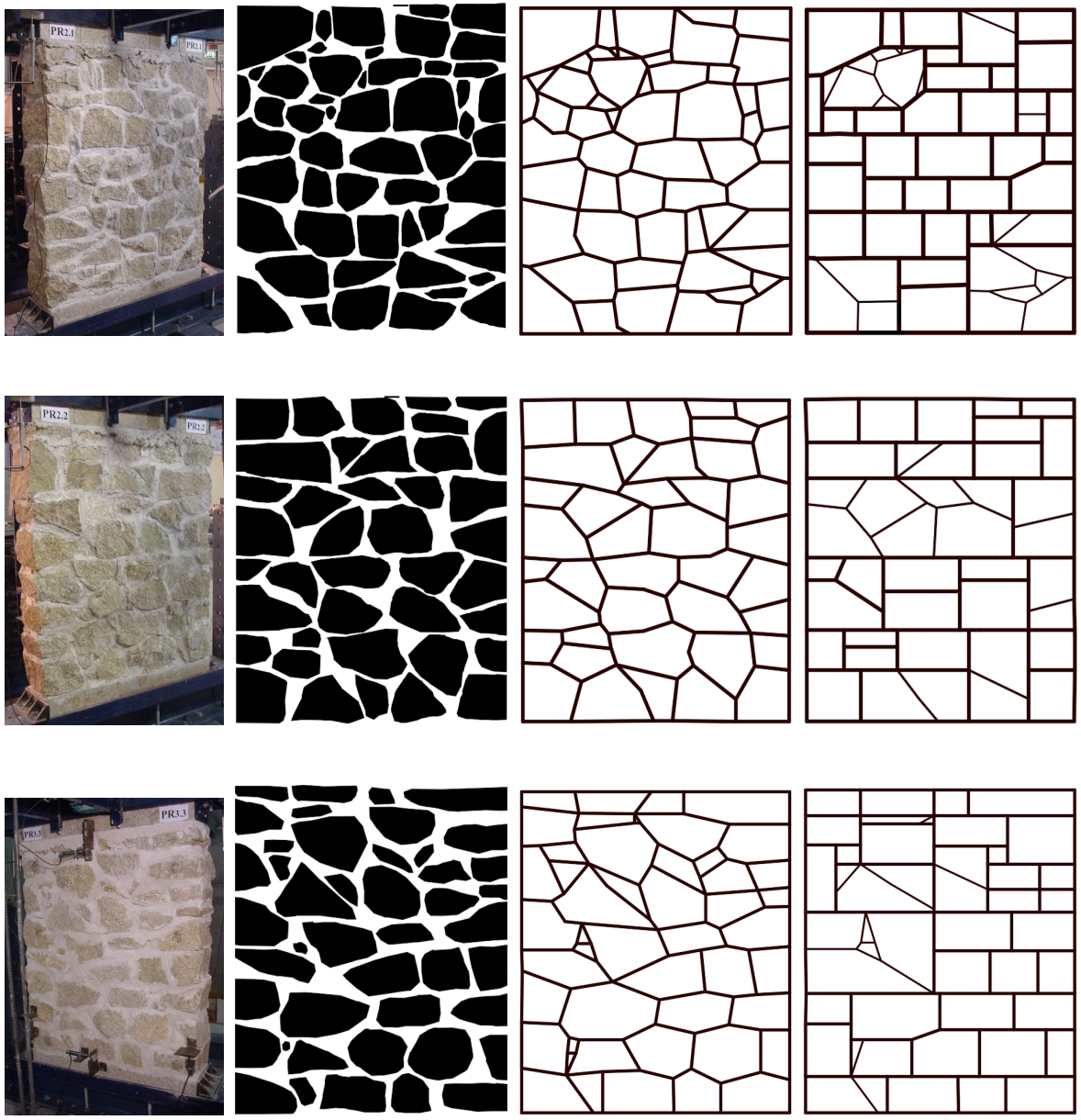

Figure 9: Real typology and deduced basic joint pattern: Walls WR1.175, WR2.175 and WR3.250 of Typology A by Vasconcelos 14, idealised stone pattern, joint pattern and basic pattern.

null hypothesis, that the generated samples and the reference sample are from the same continuous distribution, is not rejected at the $5 \%$ significance level, while for Typology A, there is still some room to improve the parameters used.

In general, this shows a good agreement between the size distributions of the generated samples to the size distributions of the reference units. This figure 


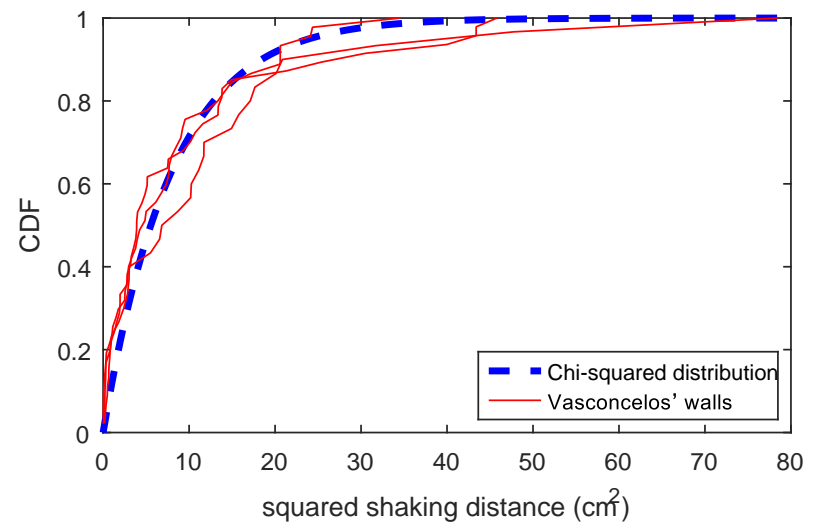

Figure 10: Comparison of the squared shaking distance of the nodes with Chi-squared distribution.

also highlights that from Typology A to E, the stones become larger and the CDF shifts from left to right.

\subsubsection{Line of minimum trace}

300 ples listed in Figure 11. For each specimen, we define three starting points and three end points along the edge. The average LMT of each specimen is plotted in Figure 13, with red markers indicating the typologies included in the Italian code and blue markers indicating the generated samples. Figure 13 shows that the LMT increases from Typology A to E, indicating an increasing degree of interlocking between the stones. Overall, there is a good agreement between the LMTs of the generated samples and the typical typologies in Figure 1.

Figure 13 further shows that the LMT increases with decreasing $\alpha$-value. To illustrate the influence of the travel cost ratio $\alpha$ between interface and mortar, 310 $\alpha=0.1$ and $\alpha=1.0$. The corresponding LMT-values are summarized in Table 1. As observed before, a value of $\alpha<1$ increases the length of the LMT (around $15 \%$ for this example, Table 11. It can also be seen from Figure 14 that the paths can vary considerably for different values of $\alpha$. 

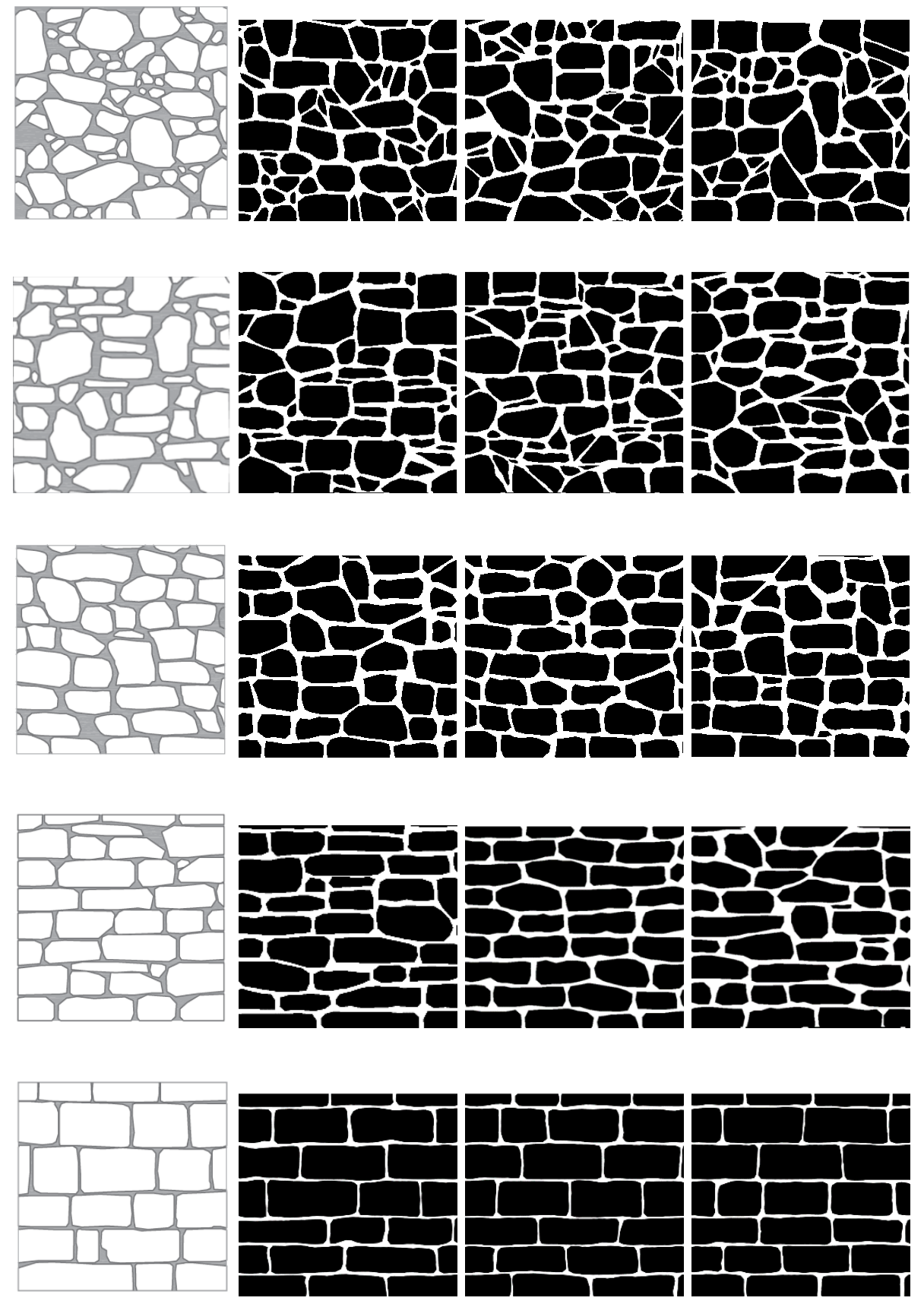

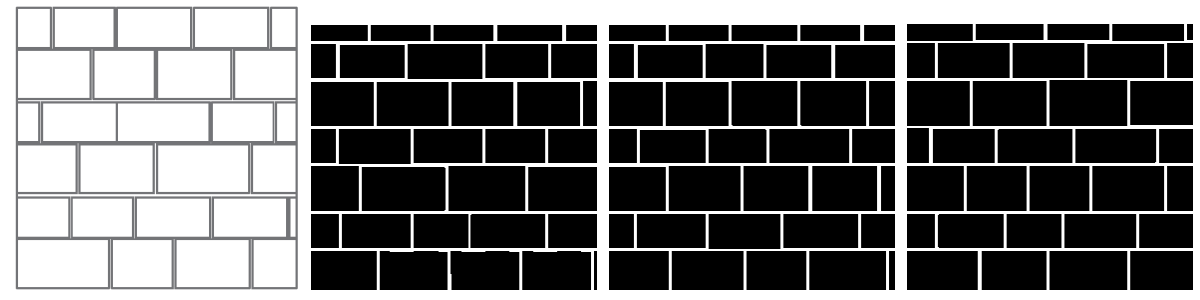

Figure 11: Generated samples for five typologies of the Italian code.
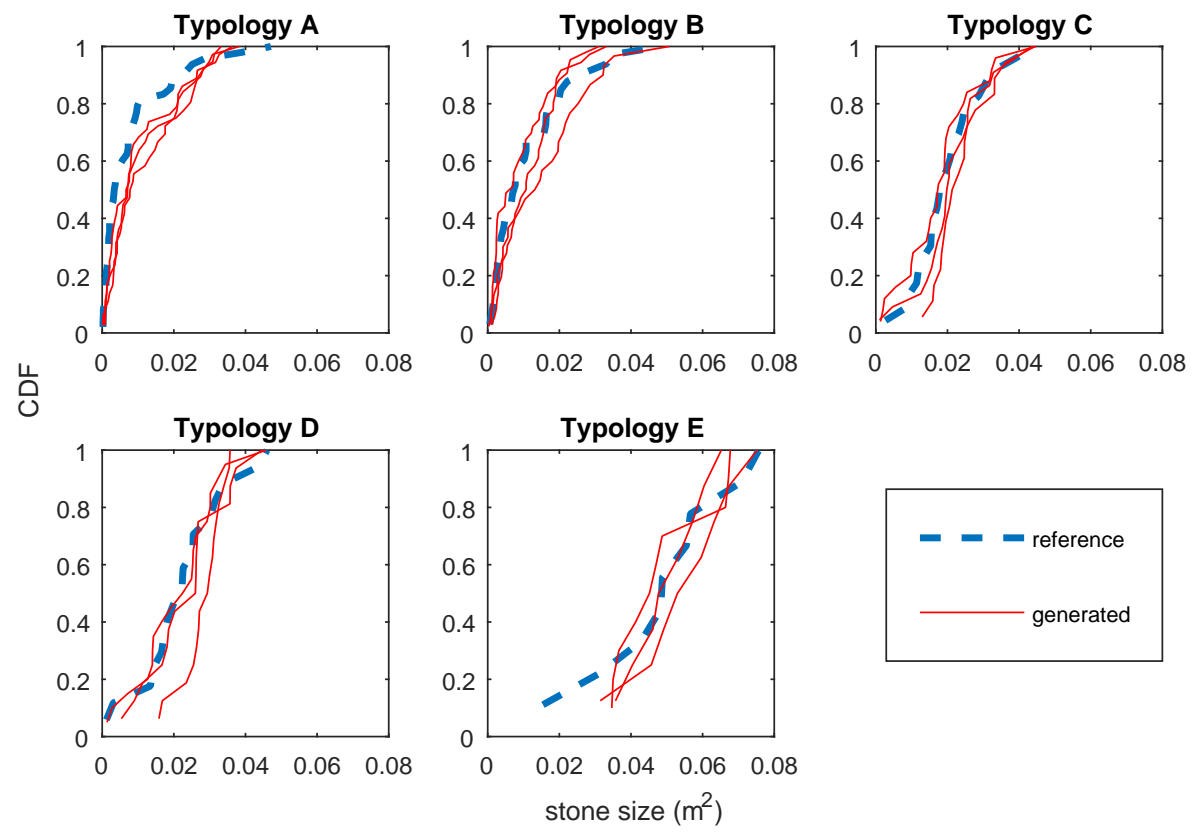

Figure 12: Comparison of the CDFs of stone sizes for the five different typologies.

\subsection{Application in finite element analysis}

To illustrate one possible application of the proposed typology generator, we further analyze the compressive strength of the generated samples in Figure 11. Within recent years, different methods have been proposed for detailed micro-modeling, e.g., 35, 11. The method used here is based on [33, with the difference that here we further consider stone damage. 


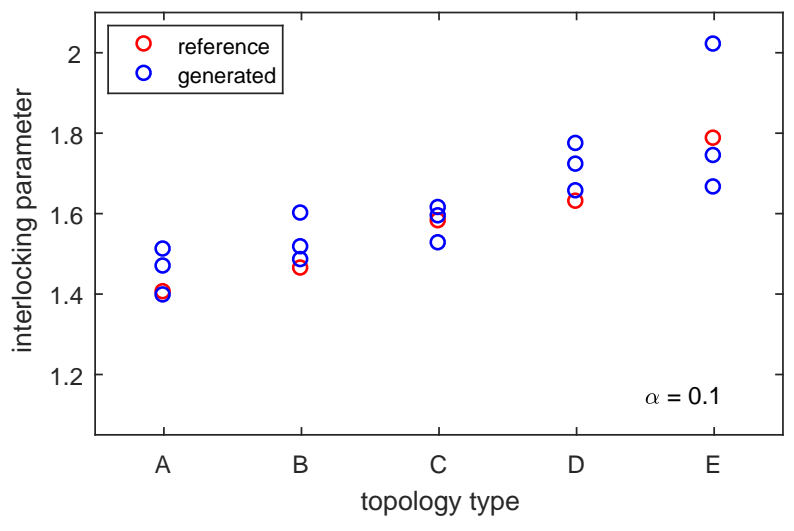

(a) $\alpha=1.0$

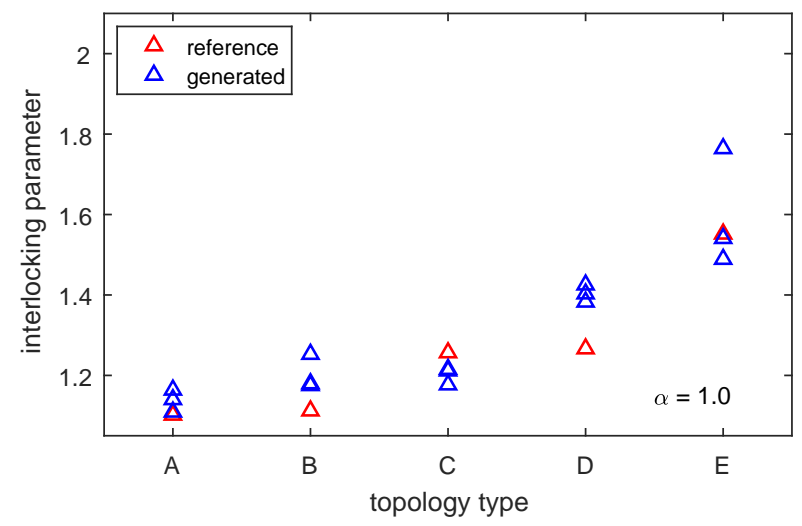

(b) $\alpha=0.1$

Figure 13: Comparison of the line of minimum trace of typologies A to E.

Table 1: Interlocking value for two typical typologies shown in Figure 14

\begin{tabular}{|c|c|c|c|c|c|}
\hline & $\alpha$ & left & mid. & right & avg. \\
\hline \multirow{2}{*}{ Figure $14 a$} & 1.0 & 1.11 & 1.13 & 1.07 & 1.10 \\
\hline & 0.1 & 1.38 & 1.37 & 1.47 & 1.41 \\
\hline \multirow{2}{*}{ Figure $14 \mathrm{~b}$} & 1.0 & 1.25 & 1.38 & 1.17 & 1.27 \\
\hline & 0.1 & 1.44 & 1.79 & 1.65 & 1.63 \\
\hline
\end{tabular}




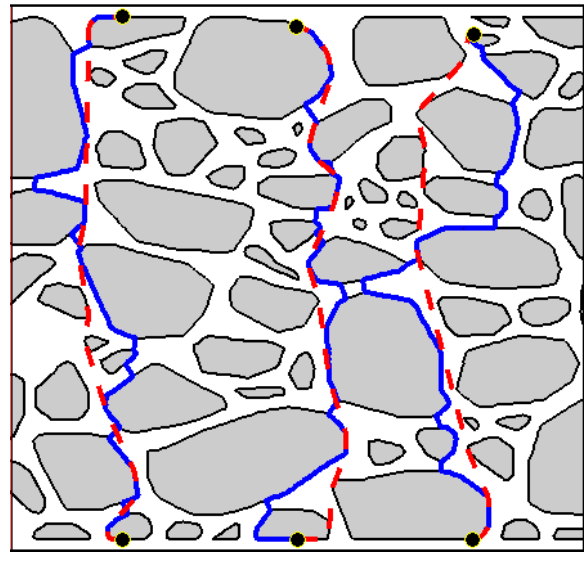

(a) typical sample for Typology A

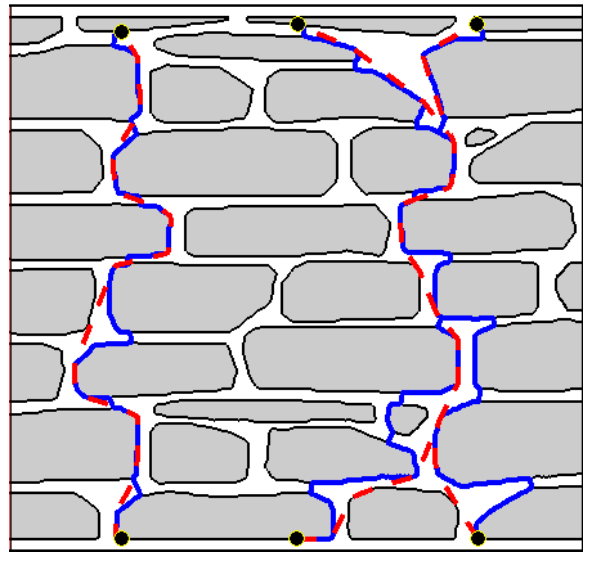

(b) typical sample for Typology D

Figure 14: Illustration of shortest path for two different typologies generated by the program. The blue lines correspond to $\alpha=0.1$ and the red lines to $\alpha=1.0$.

The material parameters have been summarized in the Tables 2 and 3 below. As indicated in the tables, most of the parameters are taken from Vasconcelos' tests [14] and numerical simulations conducted by the same group [27]. For the parameters not available, we make the following assumptions:

- The mortar is 3 times stronger than the interface (Table 3);

- We use some typical values for the elastic properties of the mortar, i.e., the elastic modulus is $500 \mathrm{MPa}$, the Poisson ratio is 0.2 , and the density of mortar is $1800 \mathrm{~kg} \mathrm{~m}^{-3}$ (Table 2);

- The second mode fracture energy is assumed to be 10 times bigger than the first mode; the cohesion is assumed to be 2 times larger than the tensile strength (Table 3).

The compressive strengths obtained from the simulation are summarized in Figure 15. When the typology changes from A to E, the mean compressive strength increases from 1.06 to $5.78 \mathrm{MPa}$, which also indicates a positive correlation with regard to the interlocking parameter. The compressive value obtained corresponds well with the range of values given by the Italian code, 
Table 2: Elastic properties

\begin{tabular}{lccc}
\hline & $\begin{array}{c}\text { Young modulus } \\
E(\mathrm{MPa})\end{array}$ & $\begin{array}{c}\text { Poison ratio } \\
\nu\end{array}$ & $\begin{array}{c}\text { Density } \\
\rho\left(\mathrm{kg} / \mathrm{m}^{3}\right)\end{array}$ \\
\hline stone & $2020 q^{a}$ & 0.2 & $2600^{b}$ \\
\hline mortar & 500 & 0.2 & 1800 \\
\hline
\end{tabular}

${ }^{a}$ Parameter taken from 27

${ }^{b}$ Parameter taken from 14

Table 3: Inelastic properties

\begin{tabular}{lccccc}
\hline & $f_{t}(\mathrm{MPa})$ & $c(\mathrm{MPa})$ & $G_{c}^{\mathrm{I}}(\mathrm{N} / \mathrm{m})$ & $G_{c}^{\mathrm{II}}(\mathrm{N} / \mathrm{m})$ & $\mu$ \\
\hline stone & $1.00^{\underline{b}}$ & 2.00 & $1000^{\underline{b}}$ & 10000 & $0.65^{\sqrt[b]{b}}$ \\
\hline mortar & 0.15 & 0.30 & 30 & 300 & 0.65 \\
\hline interface & $0.05^{\natural}$ & $0.10^{\natural}$ & 10 & $100^{\natural}$ & $0.65^{\underline{b}}$ \\
\hline
\end{tabular}

which for Typology A is $1.00-1.80 \mathrm{MPa}$ and for Typology E is $6.00-8.00 \mathrm{MPa}$ (Table C8A.2.1 in [22]). The typical failure mode for each typology is shown in Figure 16. With the increase of LMT, the failure mode changes from inter-facial damage to damage passing through the stones, which explains the significant increase of the compressive strength.

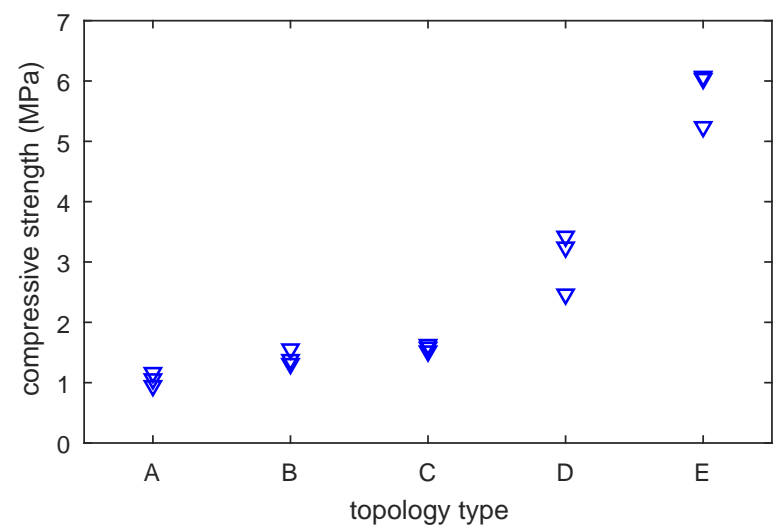

Figure 15: Comparison of compressive strengths for different typologies. 


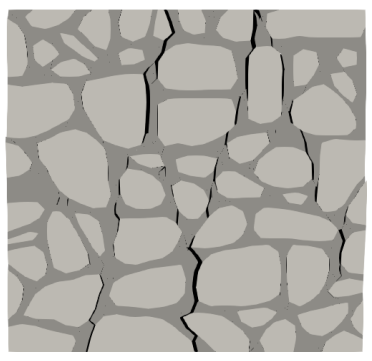

(a) Typology A

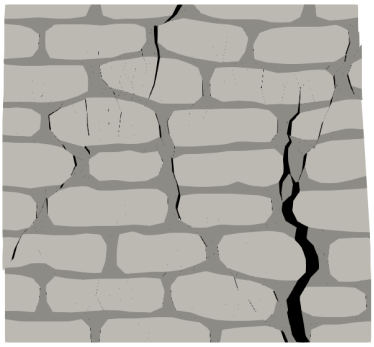

(d) Typology D

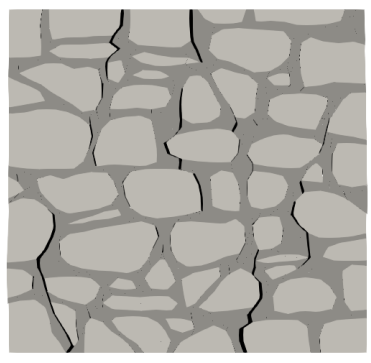

(b) Typology B

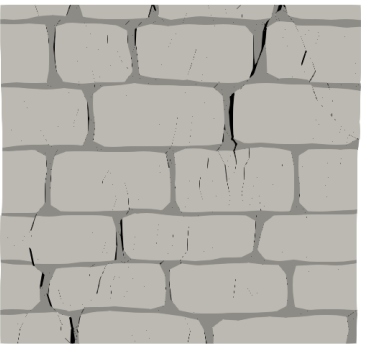

(e) Typology E

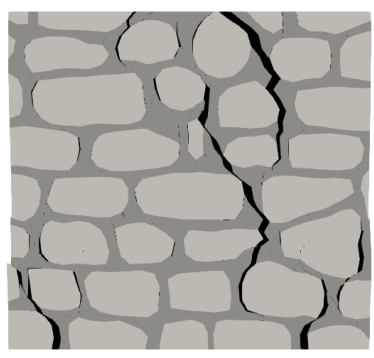

(c) Typology C

Figure 16: Typical crack patterns from compression test.

\section{Conclusions}

In this paper, we presented a new typology generator for historical stone masonry. The typology generator is built upon existing algorithms used in computer vision, i.e., [17. Compared with the previous algorithm by Miyata, our approach has the following advantages: (1) the problem of head joints aligned over several rows is resolved; (2) Voronoi splitting adds the possibility of generating more irregular patterns using the typology generator; (3) An erosion process is implemented allowing us to generate joints with varying mortar thickness.

For better characterizing the masonry typology quantitatively, we further generalized the definition of the line of minimum trace (LMT) by assigning different weights to paths through the mortar and paths following the stonemortar interface. Based on graph theory, we proposed an objective algorithm 

patterns, e.g., the patterns generated using the proposed typology generator.

For application, the typology generator was used to produce samples for five typical typologies defined in the Italian code. The generated samples are similar to the reference samples with regard to the line of minimum trace and the stone size distribution, which shows the validity and versatility of the program. The Matlab code developed in this paper is publicly available on c4science.ch, within which we also include the parameters for generating typical patterns. To illustrate further usage, we simulated compression tests for the generated samples and compared the compressive strengths for different typologies.

\section{References}

[1] D. D'Ayala, E. Speranza, Definition of collapse mechanisms and seismic vulnerability of historic masonry buildings, Earthquake Spectra 19 (3) (2003) 479-509. doi:10.1193/1.1599896

[2] G. Grünthal, European Macroseismic Scale 1992 (EMS-92), Ph.D. thesis 380 (1993). 
[3] G. Milani, R. Shehu, M. Valente, Possibilities and limitations of innovative retrofitting for masonry churches: Advanced computations on three case studies, Construction and Building Materials 147 (2017) 239-263. doi: $10.1016 / j$. conbuildmat.2017.04.075.

[4] P. Roca, M. Cervera, G. Gariup, L. Pela', Structural Analysis of Masonry Historical Constructions. Classical and Advanced Approaches, Archives of Computational Methods in Engineering 17 (3) (2010) 299-325. doi:10. 1007/s11831-010-9046-1.

[5] M. Corradi, A. Borri, A. Vignoli, Experimental study on the determination of strength of masonry walls, Construction and Building Materials 17 (5) (2003) 325-337. doi:10.1016/S0950-0618(03)00007-2.

[6] F. Vanin, D. Zaganelli, A. Penna, K. Beyer, Estimates for the stiffness, strength and drift capacity of stone masonry walls based on 123 quasi-static cyclic tests reported in the literature, Bulletin of Earthquake Engineering 15 (12) (2017) 5435-5479. doi:10.1007/s10518-017-0188-5.

[7] P. Schubert, Influence of Mortar on the Strength of Masonry, in: Brick and Block Masonry (8th IBMAC), Elsevier Applied Science, London, 1988, pp. $162-174$.

[8] W. Suaris, S. P. Shah, Strain-rate effects in fibre-reinforced concrete sub400 jected to impact and impulsive loading, Composites 13 (2). doi:10.1016/ 0010-4361(82) 90052-0.

[9] W. Mann, H. Müller, Failure of shear-stressed masonry an enlarged theory, tests and application to shear-walls, in: Proceedings of the international symposium on load bearing brickwork, London, 1980.

405

[10] C. Calderini, S. Cattari, S. Lagomarsino, In-plane strength of unreinforced masonry piers, Earthquake Engineering \& Structural Dynamics 38 (2) (2009) 243-267. doi:10.1002/eqe.860. 
[11] C. Calderini, S. Cattari, S. Lagomarsino, The use of the diagonal compression test to identify the shear mechanical parameters of masonry, Construction and Building Materials 24 (5) (2010) 677-685. doi:10.1016/j. conbuildmat.2009.11.001.

[12] P. B. Lourenço, Computational strategies for masonry structures, Ph.D. thesis, Delft University of Technology (feb 1996). doi: ISBN90-407-1221-2.

[13] G. Vasconcelos, P. B. Lourenço, In-Plane Experimental Behavior of Stone Masonry Walls under Cyclic Loading, Journal of Structural Engineering 135 (10) (2009) 1269-1277. doi:10.1061/(ASCE) ST.1943-541X.0000053

[14] G. F. M. Vasconcelos, Experimental investigations on the mechanics of stone masonry: Characterization of granites and behavior of ancient masonry shear walls, Ph.D. thesis, University of Minho (2005).

[15] C. Almeida, J. P. Guedes, A. Arêde, A. Costa, Geometric indices to quantify textures irregularity of stone masonry walls, Construction and Build-

口 ing Materials 111 (2016) 199-208. doi:10.1016/j.conbuildmat.2016. 02.038

${ }_{425}^{2}$ [16] F. Doglioni, G. Mirabella Roberti, M. Bondanelli, Definizione della Linea di Minimo Tracciato come elemento per la qualifica dell'ingranamento nel piano e fuori dal piano, Prodotto final Linea 1, progetto Reluis, Tech. rep. (2009).

[17] K. Miyata, A method of generating stone wall patterns, Systems and Computers in Japan 24 (2) (1993) 57-69. doi:10.1002/scj.4690240206

[18] A. Okabe, Spatial tessellations : concepts and applications of Voronoi diagrams, Wiley, 2000.

[19] G. Voronoi, Nouvelles applications des paramètres continus à la théorie des formes quadratiques. Deuxième mémoire. Recherches sur les parallélloèdres 
primitifs., Journal für die reine und angewandte Mathematik 134 (1908) $198-287$.

[20] D. B. West, Introduction to Graph Theory, 2nd Edition, Pearson, 2000.

[21] R. K. Ahuja, K. Mehlhorn, J. Orlin, R. E. Tarjan, Faster Algorithms for the Shortest Path Problem, J. ACM 37 (2) (1990) 213-223. doi:10.1145/ 77600.77615

[22] MIT, Ministry of Infrastructures and Transportation, Circ. C.S.Ll.Pp. No. 617 of 2/2/2009: Istruzioni per l'applicazione delle nuove norme tecniche per le costruzioni di cui al Decreto Ministeriale 14 Gennaio 2008, G.U.S.O. n.27 of 26/2/2009, No. 47, 2008 (in , Tech. rep. (2009).

[23] A. Borri, M. Corradi, G. Castori, A. De Maria, A method for the analysis and classification of historic masonry, Bulletin of Earthquake Engineering 13 (9) (2015) 2647-2665. doi:10.1007/s10518-015-9731-4.

[24] L. Binda, G. Cardani, A. Saisi, Caratterizzazione sperimentale della qualità muraria, in: Proc. of the Conference "Anidis", Bologna, 2009.

[25] G. Cardani, L. Binda, Guidelines for the evaluation of the load-bearing masonry quality in built heritage, in: L. Toniolo, M. Boriani, G. Guidi (Eds.), Built Heritage: Monitoring Conservation Management, Springer International Publishing, Switzerland, 2015, pp. 127-139.

[26] M. D. Jones, M. Farley, J. Butler, M. Beardall, Directable Weathering of Concave Rock Using Curvature Estimation, IEEE Transactions on Visual-

口 ization and Computer Graphics 16 (1) (2010) 81-94. doi:10.1109/TVCG. 2009.39.

[27] R. Senthivel, P. B. Lourenço, Finite element modelling of deformation char1 acteristics of historical stone masonry shear walls 31 (9). doi:10.1016/j. engstruct . 2009.02.046. 
[28] L. Snozzi, J.-F. Molinari, A cohesive element model for mixed mode loading with frictional contact capability, International Journal for Numerical Methods in Engineering 93 (5) (2013) 510-526.

[29] J. Li, J. Chen, Stochastic Dynamics of Structures, John Wiley \& Sons, 2009.

[30] C. Geuzaine, J.-F. Remacle, Gmsh: A 3-D finite element mesh generator with built-in pre- and post-processing facilities, International Journal for Numerical Methods in Engineering 79 (11) (2009) 1309-1331. doi:10. $1002 / \mathrm{nme} .2579$

[31] A. C. E. Reid, R. C. Lua, R. E. García, V. R. Coffman, S. A. Langer, Modelling microstructures with OOF2, International Journal of Materials and Product Technology 35 (3-4) (2009) 361-373.

[32] S. K. Ghosh, Visibility algorithms in the plane, Cambridge University Press, 2007.

475 [33] S. Zhang, S. M. Taheri Mousavi, N. Richart, J.-F. Molinari, K. Beyer, Micro-mechanical finite element modeling of diagonal compression test for historical stone masonry structure, International Journal of Solids and Structures 112 (2017) 122-132. doi:10.1016/j.ijsolstr.2017.02.014.

[34] K. J. Obermeyer, Contributors, The VisiLibity library, http://www.VisiLibity.org, release 1 (2008).

[35] N. Tarque, G. Camata, A. Benedetti, E. Spacone, Alternative approach for reproducing the in-plane behaviour of rubble stone walls, Earthquakes and Structures 13 (1) (2017) 29-38. doi:10.12989/EAS.2017.13.1.029.

[36] L.-C. Chen, G. Papandreou, I. Kokkinos, K. Murphy, A. L. Yuille, Seman485 tic image segmentation with deep convolutional nets and fully connected CRFs, in: International Conference on Learning Representations (ICLR), 2014. 